\title{
Taylor Principle and Indeterminacy under Financial Market Imperfection ${ }^{1}$
}

\author{
Ryuichi Nakagawa ${ }^{2}$ \\ Faculty of Economics \\ Kansai University
}

First Version: December 2005

Second Version: March 2006

\footnotetext{
${ }^{1}$ This paper has been presented at a seminar sponsored by Kansai Institute for Social and Economic Research. The author would like to thank Toshiki Jinushi who gave the author an opportunity to present his research. The author have benefitted from discussions with Ippei Fujiwara, Shin-ichi Fukuda, Mitsuru Iwamura, Keiichiro Kobayashi, Kazuo Mino, Kiyotaka Nakashima, Eiji Okuyama, Masashi Saito, Takashi Senda, Yosuke Takeda, Atsushi Tanaka, Toshiaki Watanabe and other seminar participants. Off course, any error remained in this paper is the sole responsibility of the author. Comments are welcome.

${ }^{2}$ Address: Faculty of Economics, Kansai University, 3-3-35 Yamate, Suita, Osaka 564-8680, Japan. Phone: (81)-6-6368-0590. Fax: (81)-6-6339-7704. E-mail: ryunaka@ipcku.kansai-u.ac.jp.
} 


\title{
Taylor Principle and Indeterminacy under Financial Market Imperfection
}

\author{
March 10, 2006
}

\begin{abstract}
This paper investigates the impact of financial market imperfection on the condition of monetary policy rules in order for the determinacy of rational-expectations equilibrium. Financial market imperfection disturbs agents' intertemporal substitution in certain cases. If the financial market is so imperfect as to change the real interest sensitivity of aggregate demand into positive, then monetary policy rules based on the Taylor principle can lead to the indeterminacy of equilibrium as follows. First, the central bank need not respond to current inflation so aggressively as the Taylor principle for determinacy. Second, the central bank must not respond to expected inflation so aggressively. Third, that imperfection might be the case with real financial markets such as the Japanese market during the 1990s, then real central banks should not be so responsive to inflation as the Taylor principle.
\end{abstract}

JEL classification: E31; E44; E52

Keywords: Taylor principle; Determinacy; Financial market imperfection 


\section{Introduction}

One of issues in the analysis of monetary policy rules is concerned with the possibility that nominal interest rate rules can generate the (local) indeterminacy of rational-expectations equilibrium, which was first argued by Sargent and Wallace[17]. Recently, influenctial Taylor[20, 21] has proposed a necessary and sufficient condition for equilibrium determinacy. It is called the Taylor principle that the central bank raise its nominal interest rate operating target more than proportionately in response to the increase in inflation rate from a target.

Meanwhile, the Taylor principle has been also casted much doubt on as the unique necessary and/or sufficient condition for determinate equilibrium.

For example, from the point of operating nominal interest rate, Bernanke and Woodford[2] and Clarida et al.[7] argue that, if the central bank responds to expected inflation, then the Taylor principle is necessary but not sufficient for determinacy. In this case, the bank must not respond extremely vigorously to expected inflation. Kiley[10] calibrates several situations in which indeterminacy can appear if the bank responds to expected inflation.

In addition, from the point of aggregate supply, others investigate the Taylor principle in models with endogenous capital accumulation, which is considered to heighten price stickiness. As a result, Dupor[8] argues that necessary and sufficient for determinacy is that the central bank responds to inflation less aggressively than the Taylor principle. Carlstrom and Fuerst[5] show that the Taylor principle leads to determinacy as long as the bank responds to current inflation. Sveen and Weinke[18] extend the Woodford's[24] firm-specific captal model, and demonstrate that the Taylor principle is necessary but not sufficient for determinacy even if the bank responds to current inflation.

However, few economists investigate whether the Taylor principle remains essential for determinacy from the point of aggregate demand. For example, if financial markets are frictional, agents' intertemporal substitutions could be disturbed so as to affect the impact of their expectations on aggregate demand. Hence such financial market imperfection might affect the condition of monetary policy rules for equilibrium determinacy, as well as the transmission mechanism of monetary policy, for example, the credit channel. ${ }^{1}$

The purpose of this paper is to investigate whether the Taylor princi-

\footnotetext{
${ }^{1}$ Bernanke and Blinder[1] introduce the credit channel that the central bank can affect economy through the financial market imperfection.
} 
ple remains necessary and/or sufficient for determinate equilibrium under financial market imperfection. First, we formulate an OLG version of New Keynesian macroeconomic model based on the Samuelson's[16] three generations model, and introduce an imperfect financial market that households expend resource to make financial contracts. This imperfection would disturb households' intertemporal substitution, and fluctuate aggregate demand as a result. Then, we calculate the conditions of monetary policy rules for equilibrium determinacy under different conditions of financial market, and provide several intuitive explanations about the relationship between the Taylor principle and financial market imperfection.

Our results are interesting in spite of the simplicity of the analysis. We will find that the real interest sensitivity of aggregate demand in the IS curve can be positive under financial market imperfection, because agents' intertemporal substituion is likely to be disturbed by the imperfection. If the financial market is so imperfect, then the Taylor principle can be unessential for determinacy as follows. First, the Taylor principle is sufficient but not necessary for determinacy if the bank responds to current inflation; that is, the bank need not be so active as the Taylor principle. Second, the Taylor principle is neither necessary nor sufficient for determinacy if the central bank responds to expected inflation; the bank must not be so active as the Taylor principle. Our results might imply it quite dangerous that the bank adheres solely to the Taylor principle when real financial markets are crucially immature or bankrupt such as the Japanese market during the 1990s.

The remainder of the paper is organized as follows. The next Section 2 outlines the structure of the OLG version of New Keynesian macroeconomic model with financial market imperfection. Section 3 calculates the determinacy conditions of monetary policy rules in the perfect financial market, and confirms that the model works consistently with the recent literature. Section 4 moves on to conditions in the imperfect financial market, and provides the intuition behind our results. Section 5 calibrates monetary policy rules that ensures equilibrium determinacy under realistic financial market imperfection. The final section summarizes the conclusions and discusses future works.

\section{The Model}

In what follows, we formulate a New Keynesian macroeconomic model based on the Samuelson's[16] overlapping generation model. Then we analyze the 
mechanism under which the financial market imperfection affects aggregate demand through disturbing agents' intertemporal substitution. After that, we also specify an aggregate supply relation.

Our economy includes representative households, firms, and a central bank. Households have an infinite sequence of overlapped three generations, who respectively optimize their lifetime utility. A financial market is so frictional that households need some resource to complete financial contracts. Firms and the central bank are owned by households, and their profits are transferred lump-sum to the owners. Firms produce differentiated goods, and conduct the Calvo-type price setting in the monopolistically competitive goods market. The central bank operates nominal interest rate in response to inflation rate.

Hereafter the steady state of a variable $X_{t}$ is represented with a capital letter without a time subscript $X$, and the percent deviation of the variable from its steady state with a small letter $x_{t}$.

\subsection{Households}

Suppose three overlapping generations of representative households: the young, middle-aged, and elderly. In period $t$, the young household has no endowment, and then borrow $-B_{1, t}$ at gross nominal borrowing rate $R_{1, t}$ in the financial market in order for current consumption $C_{1, t}$. The middleaged household supplies labor $L_{t} \in[0, \bar{L}]$ at nominal wage rate $W_{t}$, repays the previous debt $-R_{1, t-1} B_{1, t-1}$, consumes $C_{2, t}$, and saves $B_{2, t}$ at riskless gross nominal interest rate $R_{t}$ in the financial market. The elderly household consumes $C_{3, t}$ from repayment $R_{t-1} B_{2, t-1}$ from the financial market. Each generation is continuous and identical, and its population is normalized to one. The distinction between the borrowing rate $R_{1, t}$ and the riskless rate $R_{t}$ will be explained in detail in Section 2.2.

The household maximizes an expected lifetime utility:

$$
U\left(C_{1, t}, C_{2, t+1}, C_{3, t+2}, L_{t+1}\right) \equiv E_{t}\left[\sum_{k=1}^{3} \beta^{k-1} \frac{C_{k, t+k-1}^{1-\sigma}}{1-\sigma}-\gamma L_{t+1}\right],
$$

where $\beta \in(0,1)$ is a discount factor, $\sigma \in(0,+\infty)$ is relative risk aversion, or equivalently, the inverse of the intertemporal elasticity of substitution, and $\gamma \in(0,+\infty)$ is the marginal disutility of labor ${ }^{2}$.

\footnotetext{
${ }^{2}$ In reality, the utility function includes the middle-aged utility of holding real money. Here it is omitted because the demand for money is not essential for our analysis as the central bank supplies nominal money on demand, and control the riskless rate $R_{t}$ instead.
} 
All generations' budget constraints are respectively as follows:

$$
\begin{aligned}
P_{t} C_{1, t} & \leqq-B_{1, t} \\
B_{2, t} & \leqq W_{t} L_{t}-P_{t} C_{2, t}+R_{1, t-1} B_{1, t-1}+\cdots \\
P_{t} C_{3, t} & \leqq R_{t-1} B_{2, t-1}
\end{aligned}
$$

$P_{t}$ is aggregate price in period $t$. The term "..." in the middle-aged budget represents all exogenous variables including the lump-sum profits transferred from other agents. ${ }^{3}$ Note that we assume the profits to be given to the second generation.

Consequently, the first-order conditions associated with each generation's maximization in period $t$ are given by

$$
\begin{aligned}
R_{1, t} & =E_{t}\left[\beta^{-1} \Pi_{t+1}\left(\frac{C_{2, t+1}}{C_{1, t}}\right)^{\sigma}\right], \\
R_{t} & =E_{t}\left[\beta^{-1} \Pi_{t+1}\left(\frac{C_{3, t+1}}{C_{2, t}}\right)^{\sigma}\right], \\
\gamma C_{2, t}^{\sigma} & =\frac{W_{t}}{P_{t}} \\
P_{t} C_{1, t} & =-B_{1, t}, \\
P_{t} C_{3, t} & =R_{t-1} B_{2, t-1} .
\end{aligned}
$$

$\Pi_{t}$ is inflation $\frac{P_{t}}{P_{t-1}}$. Eqs. (1), (2) are young and middle-aged households' Euler equations. Eq. (3) is labor supply relation. Eqs. (4), (5) are the young and elderly households' budgets. Those will be log-linearized in Section 2.4.

\subsection{Financial Market Imperfection}

Related literature often considers that households can freely borrow and lend at the riskless rate $R_{t}$, but we will consider that the financial market is so imperfect that agents inevitably expend their resource for some physical or intermediary agency costs, in order to complete intergenerational financial contracts between the young and middle-aged households. ${ }^{4}$ Here we assume that those costs should increase as the aggregate middle-aged real saving $\frac{B_{2, t}}{P_{t}}$

\footnotetext{
${ }^{3}$ Real money holding is omitted from the budget constraints because of the same reason in footnote 2 .

${ }^{4}$ Note that intragenerational security markets is assumed to be perfect, then the representative household framework is retained in each generation even under the financial market imperfection.
} 
increases, and specify the following lending function in the financial market:

$$
\Delta\left(\frac{B_{2, t}}{P_{t}}\right)
$$

where $\Delta\left(B_{2, t} / P_{t}\right) \in\left(0, B_{2, t} / P_{t}\right]$. If the financial market is perfect, then $\Delta\left(B_{2, t} / P_{t}\right)=B_{2, t} / P_{t}$, that is, households could freely lend and borrow at the riskless rate $R_{t}$. If the market is imperfect, then $\Delta\left(B_{2, t} / P_{t}\right)<B_{2, t} / P_{t}$, that is, households must expend their resource in order to complete financial contracts. As a result, part of the saving $B_{2, t} / P_{t}$ would be exhausted; the remaining amount $\Delta\left(B_{2, t} / P_{t}\right)$ would be supplied to borrowers. However, for the simplicity of later analysis, we assume $\Delta\left(B_{2, t} / P_{t}\right) \approx B_{2, t} / P_{t}$ at the steady state equilibrium in the imperfect financial market, similar to in the perfect market.

In addition, we assume that the lending $\Delta\left(B_{2, t} / P_{t}\right)$ has $\mu \in(0,+\infty)$ th-order homogeneity in the neighborhood of the steady state equilibrium. This homogeneity $\mu$ represents the quality of the financial market imperfection, and reflects the relationship between the saving $B_{2, t} / P_{t}$ and the lending $\Delta\left(B_{2, t} / P_{t}\right)$ in Figure 1. For example, if the variable part of intermediary costs are dominant in making financial contracts and are increasing exponentially as the saving $B_{2, t} / P_{t}$ increases, then the lending $\Delta\left(B_{2, t} / P_{t}\right)$ would be concave $(0<\mu<1)$ with respect to $B_{2, t} / P_{t}$. Alternatively, if the fixed part of intermediary costs are dominant and have some economy-of-scale advantages, then $\Delta\left(B_{2, t} / P_{t}\right)$ would be convex $(\mu>1)$. Needless to mention, if there is no intermediary cost, then $\Delta\left(B_{2, t} / P_{t}\right)$ would be linear $(\mu=1)$. As a matter of convenience, we define each condition of the financial market as follows:

Definition 1 The financial market is said to be: (1) "perfect" if the market is exactly first-order homogeneous with respect to $\frac{B_{2, t}}{P_{t}}$ around the steady state $(\mu=1)$, (2) "concave" if the market is imperfect and less than first-order homogeneous around the steady state $(\mu<1)$, and (3) "convex" if the market is imperfect and more than first-order homogeneous around the steady state $(\mu>1)$.

Here we do not specify any micro-foundation behind the lending function Eq. (6) for two reasons. First, our purpose is not to investigate the influence of a specific characteristic of the financial market on monetary policy rules, but to investigate whether the financial market imperfection could affect the determinacy condition of monetary policy rules. Second, any structural specifications would be unnecessary here because our model will be loglinearized so that those structures are reduced to none. It is just necessary to 
define the homogeneity of the function around the steady state. However, we could specify any structure behind the function in reference to the existing enormous literature, if necessary.

\subsection{Equilibrium}

\subsubsection{Financial Market}

First, the equilibrium of the financial market is given by

$$
\frac{B_{1, t}}{P_{t}}+\Delta\left(\frac{B_{2, t}}{P_{t}}\right)=0 .
$$

In addition, the middle-aged borrowers' repayment equivalently coincides with the elderly lenders' revenue:

$$
R_{1, t} B_{1, t}+R_{t} B_{2, t} \equiv 0 .
$$

Using Eqs. (4), (8), Eq. (7) is transformed into

$$
R_{1, t}=R_{t} \Omega\left(C_{1, t}\right)
$$

where $\Omega\left(C_{1, t}\right) \equiv \frac{\Delta^{-1}\left(C_{1, t}\right)}{C_{1, t}}$ represents the nominal interest spread between the borrowing rate $R_{1, t}$ and the riskless rate $R_{t}$. The spread is generated by the financial market imperfection $\mu$. From Eq. (6), $\Omega\left(C_{1, t}\right) \geqq 1$, and is $\frac{1-\mu}{\mu}$ th-order homogeneous around the steady state as $\Delta$ is $\mu$ th-order homogeneous. Thus, if $\mu \lesseqgtr 1$, then $\Omega^{\prime} \gtreqless 0$.

\subsubsection{Resource Constraint}

Using Eqs. (4), (8), (9), Eq. (5) is transformed to

$$
C_{3, t}=\frac{R_{t-1} \Omega\left(C_{1, t-1}\right)}{\Pi_{t}} C_{1, t-1} .
$$

The output $Y_{t}$ is distributed to the middle-aged consumption $C_{2, t}$, the elderly one $C_{3, t}$, and the real saving $\frac{B_{2, t}}{P_{t}}$, which includes the young consumption $C_{1, t}$ and the intermediary cost. From Eqs. (4), (7), $\frac{B_{2, t}}{P_{t}}=\Delta^{-1}\left(C_{1, t}\right)=$ $\Omega\left(C_{1, t}\right) C_{1, t}$. As a result, the economy-wide resource constraint is given by

$$
Y_{t}=\Omega\left(C_{1, t}\right) C_{1, t}+C_{2, t}+C_{3, t} .
$$




\subsection{IS Curve}

Aggregate demand is determined from the IS block: Eqs. (1)-(2), (9)-(11). Now we will derive an IS curve from the log-linearization of the IS block around the steady state, and investigate how the financial market imperfection affects aggregate demand.

First, the steady state equilibria in the perfect and imperfect financial markets are equivalently given by

$$
R_{1}=R=\omega_{0}^{2}, C_{2}=\omega_{0} C_{1}, C_{3}=\omega_{0}^{2} C_{1}, \quad Y=\omega_{1} C_{1},
$$

where $\omega_{0} \equiv \beta^{\frac{1}{\sigma-2}}$ and $\omega_{1} \equiv 1+\omega_{0}+\omega_{0}^{2}$. Here several trivial assumptions are made about the steady state equilibrium, for the tractability of loglinearization. First, our attention is restricted to the steady state with zero inflation target $\Pi=1$. Second, as $\Delta\left(B_{2, t} / P_{t}\right) \approx B_{2, t} / P_{t}$ at the steady state is assumed in Section 2.2, $\Omega\left(C_{1}\right) \approx 1$ is assumed in both perfect and imperfect financial markets. Third, $\sigma<2$ is assumed for $R>1$ at the steady state. These assumptions have no influence on our analysis.

From Eq. (12), the log-linearized IS blocks in both perfect and imperfect financial markets are equivalently given by

$$
\begin{aligned}
\mu^{-1} c_{1, t} & =\eta\left(E_{t} c_{2, t+1}-\sigma^{-1}\left(r_{t}-E_{t} \pi_{t+1}\right)\right) \\
c_{2, t} & =E_{t} c_{3, t+1}-\sigma^{-1}\left(r_{t}-E_{t} \pi_{t+1}\right) \\
c_{3, t} & =\mu^{-1} c_{1, t-1}+r_{t-1}-\pi_{t} \\
y_{t} & =\omega_{1}^{-1}\left(\mu^{-1} c_{1, t}+\omega_{0} c_{2, t}+\omega_{0}^{2} c_{3, t}\right)
\end{aligned}
$$

where $\eta \equiv \frac{\sigma}{1+\mu(\sigma-1)}$. Eq. (13) is the young Euler equation. Note that the equation also represents the young demand for the log-linearized middleaged saving, because the saving is equal to $\mu^{-1} c_{1, t}$. Eq. (14) is the middleaged Euler equation. Eq. (15) is the elderly budget. Eq. (16) is the resource constraint. $B_{1, t}, B_{2, t}$, and $R_{1, t}$ are completely eliminated.

Finally, substituting Eqs. (13), (15) into Eq. (14), we can simplify the IS block to the following OLG version of IS curve:

$$
c_{2, t}=\eta E_{t} c_{2, t+1}-\left[\sigma^{-1}(1+\eta)-1\right]\left(r_{t}-E_{t} \pi_{t+1}\right),
$$

which is an equation of the middle-aged consumption $c_{2, t}$.

It is clear that the financial market imperfection $\mu$ (or $\eta$ ) has an impact on aggregate demand. The most important is that the real rate sensitivity of aggregate demand $-\left[\sigma^{-1}(1+\eta)-1\right]$ is influenced by the imperfection as follows: 
Lemma 1 If the financial market is so imperfect as $\sigma^{-1}(1+\eta)<1$, then the real rate sensitivity of aggregate demand can be positive, that is, the increase in the real rate $r_{t}-E_{t} \pi_{t+1}$ can expand the middle-aged consumption $E_{t} c_{2, t}$ and aggregate demand.

We can also regard $\left[\sigma^{-1}(1+\eta)-1\right]$ as the economy-wide intertemporal elasticity of substitution. Then Lemma 1 implies the case that the elasticity can be negative.

The intuition behind Lemma 1 can be explained from the IS block Eqs. (13)-(16). Given $\pi_{t}$ and $r_{t}$, an independent increase in the real rate has negative and positive effects on aggregate demand. The negative effect is to reduce the young demand for lending in the financial market (Eq. (13)). This decrease also reduces the current middle-aged consumption $c_{2, t}$ through the contraction of their saving and future consumption $E_{t} c_{3, t+1}$ (Eqs. (14), (15)). This negative effect is represented as $\sigma^{-1}(1+\eta)$ in the coefficient of the real rate. Adversely, the positive effect is to expand the current elderly consumption $c_{3, t}$ (Eq. (15)). This increase is reflected as -1 in the coefficient. If the financial market is perfect $(\mu=1)$, then the real rate sensitivity always is negative $(-(2 / \sigma-1)<0)$. If the market is imperfect $(\mu \neq 1)$, then the young intertemporal substitution can be disturbed by the imperfection so as to change the sensitivity into positive.

\section{$2.5 \quad$ Firms}

The firm is infinitely operated and owned by the middle-aged, then its profit is transferred lump-sum to them. A firm $i \in[0,1]$ hires identical labor $L_{t}(i)$ from the middle-aged competitively, and produces a differenciated good $Y_{t}(i)$, which is supplied monopolistically competitively to the good market. Each firm must keep its good price equal to the previous one with probability $\theta \in\left(\frac{1}{2}, 1\right]$ in each period, irrespective of how long the price has been fixed since the firm last changed its price (Calvo[4]). ${ }^{5}$ The aggregated final goods $Y_{t} \equiv \int_{0}^{1} Y_{t}(i) d i$ are consumed by households. The labor demand is also aggregated as $L_{t} \equiv \int_{0}^{1} L_{t}(i) d i$.

Each firm has an identical production function $Y_{t}(i)=f\left(L_{t}(i)\right)$ with the first-order homogeneity around the steady state. Then, the firm $i$ 's real marginal cost of output $M C_{t}(i)$ is calculated as $M C_{t}(i)=\frac{W_{t} / P_{t}}{f^{\prime}\left(L_{t}(i)\right)}=$ $\frac{\gamma C_{2, t}^{\sigma}}{f^{\prime}\left(L_{t}(i)\right)}$, from the labor supply Eq. (3). As $f^{\prime}\left(L_{t}(i)\right)$ is zero-order homogeneous, the real marginal cost of output is identical across firms and is

${ }^{5} \theta \in\left(\frac{1}{2}, 1\right]$ is assumed for the simplicity of later analysis. 
log-linearized as follows:

$$
m c_{t}=\sigma c_{2, t} .
$$

The log-linearized AS relation between $m c_{t}$ and $\pi_{t}$ is derived according to Gali and Gertler[9]:

$$
\pi_{t}=\lambda m c_{t}+\beta E_{t} \pi_{t+1},
$$

where $\lambda \equiv \frac{(1-\theta)(1-\beta \theta)}{\theta} \in\left[0, \frac{1}{2}\right)$. Substituting Eq. (18) into Eq. (19), we can obtain the following $O L G$ version of the New Keynesian Phillips curve:

$$
\pi_{t}=(\lambda \sigma) c_{2, t}+\beta E_{t} \pi_{t+1},
$$

in which $\pi_{t}$ depends upon the middle-aged consumption $c_{2, t}$.

\section{Determinacy Condition in the Perfect Financial Makret}

Now we consider the conditions of monetary policy rules necessary and/or sufficient for determinate equilibrium under financial market imperfection. We begin with considering the conditions in the perfect financial market in order to clarify that our OLG vertion of the New Keynesian model provides consistent results to the existing literature. In the next Section 4, we move on to the condition in the imperfect market. For the tractability of later analysis, we assume that $\beta$ is approximately equal to one, but not exactly equal to one, $\beta \approx 1$.

We define two type of nominal interest rate rules that the central bank adopts. One is a current-looking rule:

$$
r_{t}=\phi_{\pi} \pi_{t}
$$

where $\phi_{\pi} \in[0,+\infty)$ is a response coefficient to inflation rate. The other is a forward-looking rule:

$$
r_{t}=\phi_{\pi} E_{t} \pi_{t+1} .
$$

First, we consider the condition for determinacy if the central bank adopts the current-looking rule. Our economy includes the IS curve Eq. (17), the Phillips curve Eq. (20), and the monetary policy Eq. (21), in which three variates $\left(c_{2, t}, \pi_{t}, r_{t}\right)$ are non-predetermined endogenous variables. Then, for rational-expectations equilibrium to be determinate, all the eigenvalues of our model must lie outside the unit circle (Blanchard and Kahn[3]). The 
derivation of determinacy conditions can be summarized in Appendix A in reference to Woodford[24, p.670]; the conditions of the current-looking rule are calculated in Appendix B.

As a result, in the perfect financial market $(\mu=1)$, rational-expectations equilibrium is determinate if and only if the response coefficient $\phi_{\pi}$ satisfies

$$
\phi_{\pi}>1
$$

The detailed proof is in Appendix B \& B.1. Eq. (23) is none other than the Taylor principle. This result proves our model to be consistent with the existing literature.

It is clear-cut why the Taylor principle be essential for determinate equilibrium. Suppose that there happened a sunspot shock such that households expected an increase in future inflation $E_{t} \pi_{t+1}$ in absence of any fundamental shocks. That forecast would lead to the decrease in real rate, which would expand output and raise inflation. If the central bank raises the nominal interest rate sufficiently, then those expansions would be suppressed as to avoid a self-fulfilling inflation. Therefore, the Taylor principle is necessary and sufficient for determinate equilibrium. ${ }^{6}$

Next, we calculate the condition for determinacy if the central bank adopts the forward-looking rule. Similarly, our economy (Eqs. (17), (20), $(22))$ includes three non-predetermined endogenous variables $\left(c_{2, t}, \pi_{t}, r_{t}\right)$. The conditions of the current-looking rule are calculated in Appendix C.

The same methodology provides a result that rational-expectations equilibrium is determinate if and only if the response coefficient $\phi_{\pi}$ satisfies

$$
1<\phi_{\pi}<1+\frac{4}{\lambda(2-\sigma)} .
$$

The proof is in Appendix C \& C.1.

Eq. (24) indicates that the central bank must follow the Taylor principle, but not respond extremely vigorously to expected inflation rate for determinate equilibrium. We will call this rule the bounded Taylor principle

\footnotetext{
${ }^{6}$ Exactly, the necessity and sufficiency of the Taylor principle is explained as follows. For example, one percent increase in $E_{t} \pi_{t+1}$ eventually leads to $\frac{1+\lambda(2-\sigma)}{1+\phi_{\pi} \lambda(2-\sigma)}$ percent selffulfilling increase in $\pi_{t}$. This means that, if $\phi_{\pi}>1$, then $\left|\pi_{t}\right|<\left|E_{t} \pi_{t+1}\right|$. But, this equilibrium contradicts households' rational-expectations, because inflation must be expected to converge to the steady state over time, $\left|\pi_{t}\right|>\left|E_{t} \pi_{t+1}\right|>\left|E_{t} \pi_{t+2}\right|>\cdots$. Otherwise, the equilibrium would violate the resource constraint Eq. (16) in the future. Therefore, if $\phi_{\pi}>1$, then this self-fulfilling equilibrium cannot appear, and rational-expectations equilibrium is determinate at the fundamental one, and vice versa.
} 
hereafter. This result also proves our model to be consistent to the literature (e.g., Woodford[24]). ${ }^{7}$

It is also intuitive why the Taylor principle should be bounded when the central bank is forward-looking. Suppose again the previous sunspot shock that households expected an increase in future inflation. The rise in expected inflation would not lead to the expansions of output and inflation, because the central bank immediately responds to expected inflation and raises nominal and real rate. If $\phi_{\pi}$ is extremely large, then the rise in expected inflation would rather fluctuate economy toward deep recession. Therefore, the bounded Taylor principle is necessary and sufficient for determinacy under the forward-looking rule.

In summary, we have confirmed that our model has exactly the same characteristics as those in recent studies. We can therefore regard that our later results should be evolved from the financial market imperfection, not from our OLG framework.

\section{Determinacy Condition in the Imperfect Finan- cial Market}

In what follows, we consider the condition of monetary policy rules necessary and/or sufficient for determinate equilibrium under the financial market imperfection. As is explained in Definition 1, we define two type of imperfection: the concavity $(\mu<1)$ and convexity $(\mu>1)$. For both cases, determinacy conditions will be obtained respectively.

In analogy with the last section, the central bank adopts the currentor forward-looking rules. The economy includes three non-predetermined endogenous variables $\left(c_{2, t}, \pi_{t}, r_{t}\right)$. The derivation of determinacy conditions is therefore summarized in Appendix A.

\subsection{Current-looking Rule}

First, we calculate the conditions for determinacy when the central bank adopts the current-looking rule Eq. (21).

\footnotetext{
${ }^{7}$ Woodford's proposition 4.5 can be exactly transformed into Eq. (24) as our model is compared with his model. As for the bounded Taylor principle, see also Bernanke and Woodford[2] and Clarida et al.[7].
} 


\subsubsection{Concave Imperfection}

Lemma 2 In the concave financial market $(\mu<1)$, equilibrium is determinate if and only if the response coefficient $\phi_{\pi}$ satisfies

$$
\phi_{\pi}>\max \left\{1, z_{1}, z_{2}\right\},
$$

where $z_{1} \equiv-\frac{(1-\sigma)(1-\mu)}{\lambda\left(1-\mu(1-\sigma)^{2}\right)}, z_{2} \equiv-1-\frac{2(1+\sigma-\mu(1-\sigma))}{\lambda\left(1-\mu(1-\sigma)^{2}\right)}$.

The proof is in Appendix B \& B.2.

Lemma 2 suggests that the central bank should respond to inflation rate in the concave market at least as aggressively as the Taylor principle. We will call this rule the quasi-Taylor principle hereafter. The intuition behind the quasi-Taylor principle is very intuitive. Suppose another sunspot shock such that households expected an increase in future middle-aged consumption $E_{t} c_{2, t+1}$ without any fundamental shocks. If the financial market is so imperfect as $\eta>1$, then this shock could expand the current consumption $c_{2, t}$ larger than in the perfect market, as is seen in Eq. (17). Therefore, the central bank must be at least as active as the Taylor principle.

However, it is clear that the concave financial market does not essentially affect the condition of monetary policy rules for determinacy. This is because Lemma 2 is reduced to Eq. (23) as $\mu$ approaches to one.

\subsubsection{Convex Imperfection}

Lemma 3 In the convex financial market $(\mu>1)$, equilibrium is determinate if and only if the response coefficient $\phi_{\pi}$ satisfies

$$
\begin{aligned}
& \text { 1. } \phi_{\pi}>\max \left\{1, z_{1}, z_{2}\right\} \\
& \text { for } 0<\sigma \leqq 1-\frac{1}{\sqrt{\mu}} \text { or } \frac{\mu-1}{\mu+1} \leqq \sigma \leqq 1+\frac{1}{\sqrt{\mu}}, \\
& \text { 2. } \phi_{\pi}>\max \left\{1, z_{1}, z_{2}\right\} \text { or } 0<\phi_{\pi}<\min \left\{1, z_{1}, z_{2}\right\} \\
& \text { for } 1-\frac{1}{\sqrt{\mu}}<\sigma<\frac{\mu-1}{\mu+1} \text { or } 1+\frac{1}{\sqrt{\mu}}<\sigma<2,
\end{aligned}
$$

where $z_{1} \equiv-\frac{(1-\mu)(1-\sigma)}{\lambda\left(1-\mu(1-\sigma)^{2}\right)}, z_{2} \equiv-1-\frac{2(1+\sigma-\mu(1-\sigma))}{\lambda\left(1-\mu(1-\sigma)^{2}\right)}$.

The proof is in Appendix B \& B.3.

Lemma 3.1 is analogous to Lemma 2, but the most emphasized and different from previous results is Lemma 3.2 that $0<\phi_{\pi}<\min \left\{1, z_{1}, z_{2}\right\}$ can be another sufficient condition for determinate equilibrium. This means that the quasi-Taylor principle is sufficient but not necessary for determinacy in the convex financial market. In other words, the central bank need not 
respond to current inflation as aggressively as the standard Taylor principle Eq. (23).

Why is there the case that the Taylor principle is unnecessary? Before answering the question, we should consider what happens in the financial market of Lemma 3.2.

Lemma 4 If the financial market is so convex as Lemma 3.2, then the real rate sensitivity of aggregate demand can be positive.

Proof. If and only if $1-\frac{1}{\sqrt{\mu}}<\sigma<\frac{\mu-1}{\mu+1}$ or $1+\frac{1}{\sqrt{\mu}}<\sigma<2$, then $0<\sigma^{-1}(1+\eta)<1$, which corresponds to Lemma 1 .

Therefore, we can conclude about the determinacy condition of the currentlooking rule under the financial market imperfection as follows:

Proposition 1 If the financial market is so convexly imperfect as to change the real rate sensitivity of aggregate demand into positive, then the central bank need not be necessarily as responsive to current inflation as the Taylor principle.

Now it is clear why the Taylor principle becomes unnecessary for determinate equilibrium in the financial market of Lemma 3.2. Suppose again the previous sunspot shock that households expected an increase in future inflation without any fundamental shocks. Here, the rise in expected inflation would have two opposite effects on current inflation. First, to raise inflation directly in the Phillips curve. Second, to lower current inflation indirectly through the decrease in the middle-aged consumption in the IS curve. The latter reflects Lemma 4 . If those effects are totally positive, then the mechanism is analogous with Lemma 2, in which the central bank should adopt the quasi-Taylor principle $\phi_{\pi}>\max \left\{1, z_{1}, z_{2}\right\}$. Adversely, if those effects are totally negative, then the rise in expected inflation eventually leads to current deflation (Lemma 4). The more vigorously the central bank responds to this deflation, the more nominal and real rates decrease in response to this self-fulfilling deflation. As a result, this decrease in real rate would accelerate the self-fulfilling deflation over time. Therefore, if the real rate sensitivity of aggregate demand is positive, then the Taylor principle can be unnecessary for determinate equilibrium. ${ }^{8}$

\footnotetext{
${ }^{8}$ Exactly, one percent increase in $E_{t} \pi_{t+1}$ leads to $\frac{1+\lambda \sigma\left(\sigma^{-1}(1+\eta)-1\right)}{1+\phi_{\pi} \lambda \sigma\left(\sigma^{-1}(1+\eta)-1\right)}$ percent increase in $\pi_{t}$. Note that $\sigma^{-1}(1+\eta)<1$ in Lemma 3.2. As is explained in footnote 6 , $\left|\frac{1+\lambda \sigma\left(\sigma^{-1}(1+\eta)-1\right)}{1+\phi_{\pi} \lambda \sigma\left(\sigma^{-1}(1+\eta)-1\right)}\right|<1$ is necessary for determinate equilibrium. Therefore, the equilibrium is determinate if $\phi_{\pi}$ is enough larger than one or if $\phi_{\pi}$ is enough smaller than one, and vice versa.
} 
Proposition 1 might be reasonable if we remind that the central bank adopts a monetary policy rule in order to control agents' rational expectations. If they do intertemporal substitution along with their rational expectations, then the bank must respond aggressively to inflation which depends upon their expectations. However, if they can not behave in that way because of the financial market imperfection, the central bank need not respond to such a expectational variable as aggressively as before. Therefore, the Taylor principle can be unnecessary if the intertemporal substitution is disturbed by the financial market imperfection.

Finally, the determinacy conditions of the current-looking rule (Eq. (23), Lemma $2 \& 3$ ) are summarized in Figure 2. The figure describes the conditions of the response coefficient $\phi_{\pi}$ for determinacy with respect to the values of $\sigma$ and $\mu$. Then, we conclude:

Corollary 1 The more convex the financial market imperfection is, the less necessary the Taylor principle is for determinate equilibrium under the current-looking rule.

\subsection{Forward-looking Rule}

Next, we consider the condition for determinacy if the central bank adopts the forward-looking rule Eq. (22). In the same way as before, we consider the concave $(\mu<1)$ and convex $(\mu>1)$ financial market, respectively.

\subsubsection{Concave Imperfection}

Lemma 5 In the concave financial market $(\mu<1)$, equilibrium is determinate if and only if the response coefficient $\phi_{\pi}$ satisfies

1. $1<\phi_{\pi}<z_{3}$ for $0<\sigma \leqq 1$,

2. but equilibrium is always indeterminate for $1<\sigma<2$,

where $z_{3} \equiv 1+\frac{2(1+\sigma-\mu(1-\sigma))}{\lambda\left(1-\mu(1-\sigma)^{2}\right)}$.

The proof is in Appendix C \& C.2.

Similar to Lemma 2, it is clear that the concave market does not essentially affect the condition of monetary policy rules for determinate equilibrium. This is because Lemma 5.1 is reduced to the bounded Taylor principle Eq. (24) as $\mu$ approaches to one.

In contrast to Lemma 2, Lemma 5.2 also indicates a case that equilibrium is always indeterminate for any $\phi_{\pi}$. This result is consistent with Kiley[10], 
who shows that, if the central bank responds to expected inflation, then indeterminacy can arise with any response coefficients of monetary policy rules. For this indeterminacy to be avoided, the central bank would have to respond to another variable such as output gap to ensure determinacy.

\subsubsection{Convex Imperfection}

Lemma 6 In the convex financial market $(\mu>1)$, equilibrium is determinate if and only if the response coefficient $\phi_{\pi}$ satisfies

$$
\begin{aligned}
& \text { 1. } 1<\phi_{\pi}<z_{3} \quad \text { for } 0<\sigma \leqq 1-\frac{1}{\sqrt{\mu}} \text { or } 1 \leqq \sigma \leqq 1+\frac{1}{\sqrt{\mu}} \text {, } \\
& \text { 2. } \max \left\{0, z_{3}\right\}<\phi_{\pi}<1 \quad \text { for } 1-\frac{1}{\sqrt{\mu}}<\sigma \leqq \frac{\mu-1}{\mu+1} \text { or } 1+\frac{1}{\sqrt{\mu}}<\sigma<2 \text {, } \\
& \text { 3. but equilibrium is always indeterminate for } \frac{\mu-1}{\mu+1}<\sigma<1 \text {, }
\end{aligned}
$$

where $z_{3} \equiv 1+\frac{2(1+\sigma-\mu(1-\sigma))}{\lambda\left(1-\mu(1-\sigma)^{2}\right)}$.

The proof is in Appendix C \& C.3.

Lemma 6.1 is analogous to Lemma 5 and is the bounded Taylor principle in the imperfect financial market. For the same reason as Lemma 5.2, Lemma 6.3 indicates a case that equilibrium is always indeterminate for any $\phi_{\pi}$.

The most emphasized and different from Lemma 5 is Lemma 6.2 that $\max \left\{0, z_{3}\right\}<\phi_{\pi}<1$ is the unique necessary and sufficient condition for determinate equilibrium. This means that the central bank must not respond to expected inflation as aggressively as the Taylor principle.

Therefore, as is the case with Proposition 1, we conclude about the determinacy condition of the forward-looking rule under the financial market imperfection as follows:

Proposition 2 If the financial market is so convexly imperfect as to change the real rate sensitivity of aggregate demand into positive, then the central bank must not be as responsive to expected inflation as the Taylor principle.

The intuition behinde Proposition 2 is explained as follows. Suppose again the sunspot shock that households expected an increase in $E_{t} \pi_{t+1}$ without any fundamental shocks. As is explained in Section 3, the rise in expected inflation raises real rate directly, as the central bank responds to expected inflation. This real rate would affect the middle-aged consumption 
negatively under the perfect financial market. But, if the financial market is so convex as Lemma 6.2, then real rate would affect positively, as is explained in Section 4.1.2. Then, the initial rise in expected inflation would raise current inflation, not only one-for-one directly in the Phillips curve, but also indirectly through the increase in aggregate demand in the IS curve. The latter effect increases as $\phi_{\pi}$ increases. Consequently, the more vigorously the central bank responds to expected inflation, the more the initial rise in expected inflation would accelerate this self-fulfilling inflation. Therefore, the Taylor principle can be neither necessary nor sufficient for determinate equilibrium. ${ }^{9}$

Finally, the determinacy conditions of the forward-looking rule (Eq. (24), Lemma $5 \& 6$ ) are also summarized in Figure 3. Then, we conclude:

Corollary 2 The more convex the financial market imperfection is, the more the Taylor principle can be neither necessary nor sufficient for determinate equilibrium under the forward-looking rule.

Summarizing Section 4, we can conclude about the determinacy conditions of monetary policy rules as follows: If the financial market is so imperfect as to disturb households' intertemporal substitution, then the real rate sensitivity of aggregate demand can become positive. If the sensitivity is positive, then (1) the central bank need not be as responsive to current inflation as the Taylor principle, (2) the bank must not be as responsive to expected inflation as the Taylor principle, and (3) those situations would be more prevailing as the financial market becomes more convexly imperfect.

\section{Calibration}

This section calibrates the response coefficient $\phi_{\pi}$ ensuring equilibrium determinacy with respect to the financial market imperfection $\mu$.

Relevant structural parameters are $\{\beta, \theta, \sigma\}$. Simply, we set $\beta=1$ and $\theta=0.6$. From Figure 2 and 3 , determinacy conditions depend upon whether $\sigma$, the inverse of the intertempral elasticity of substitution, is more than one

\footnotetext{
${ }^{9}$ Exactly, one percent increase in $E_{t} \pi_{t+1}$ leads to $1-\left(\phi_{\pi}-1\right) \lambda \sigma\left(\sigma^{-1}(1+\eta)-1\right)$ percent increase in $\pi_{t}$. Note that $\sigma^{-1}(1+\eta)<1$ in Lemma 3.2. As is explained in footnote 6 , $\left|1-\left(\phi_{\pi}-1\right) \lambda \sigma\left(\sigma^{-1}(1+\eta)-1\right)\right|<1$ is necessary for determinate equilibrium. Then, equilibrium is determinate if $\phi_{\pi}<1$, and vice versa.
} 
or not. However, related studies estimate $\sigma$ to be 1 to $3 .{ }^{10}$ Then we set $\sigma=1.99$ on average, provided the assumption $\sigma<2$.

Figure 4 shows the determinacy conditions under the current-looking rule. Panel (a) is the result under the current-looking rule, and Panel (b) is the one under the forward-looking rule. This figure shows only the region that has realistic value of $\phi_{\pi}$.

It is clear that determinacy conditions crucially depend upon the financial market imperfection $\mu$. If the financial market is perfect $(\mu=1)$, then the Taylor principle $\phi_{\pi}>1$ is the unique determinacy condition under the both current- and forward-looking rules. Meanwhile, the more concave the market is $(\mu<1)$, the more aggressive the current-looking rule must be than the Taylor principle. The forward-looking rule cannot ensure determinate equilibrium. On the other hand, if the financial market is convex $(\mu>1)$, both the current- and forward-looking rules must be less aggressive than the Taylor principle. ${ }^{11}$

Most fundamental question would be whether real financial markets are concave or convex. As an example, we estimate the parameter $\mu$ from Japanese financial data in the 1990s, when Japanese financial markets were deeply bankrupt. The details of estimation are as in Appendix D. Table 1 shows estimation results. We estimate $\mu$ with respect to not only all, but also each type of borrowers, because the financial market imperfection seems to depend upon the type of borrowers. Ogawa and Kitasaka[14] indicate that the loans to construction and real estate industries were more frictional than the loans to manufacturing and wholesale \& retail trade industries. Our results suggest that real fiancial markets might be convexly imperfect, and that, the more frictional the market is, the more convex it might be.

In summary, if real financial markets are convexly imperfect, then the central bank should not be so responsive to current or expected inflation as the Taylor principle. This situation might be likely in real imperfect financial markets like the Japanese financial distress in the 1990s.

\footnotetext{
${ }^{10}$ See, for example, Ogaki and Reinhalt[13] and Vissing-Jorgenson[23] for U.S. economy; and Kitamura and Fujiki[11] and Okubo[15] for Japanese economy.

${ }^{11}$ Note that the figure does not show all conditions. As is depicted in Figure 2, the current-looking rule must have the other condition $\phi_{\pi}>\max \left\{1, z_{1}, z_{2}\right\}$ in the convex market. However, Panel (a) ignores the condition because it leads to an unrealistically aggressive current-looking rule. For example, if $\mu=1.5$, then $\phi_{\pi}>\max \left\{1, z_{1}, z_{2}\right\} \approx 70$. Similarly, the forward-looking rule must have the other condition $1<\phi_{\pi}<z_{3}$ in the convex market, as is in Figure 3. However, the above parameter values leads to $z_{3}<0$, which nullifies the condition $1<\phi_{\pi}<z_{3}$.
} 


\section{Concluding Remarks}

In this paper, we investigated the impact of financial market imperfection on the condition of monetary policy rules necessary for the determinacy of rational-expectations equilibrium. We introduced an imperfect financial market into an OLG version of New Keynesian macroeconomic model. Then, we examined the conditions of monetary policy rules to realize determinate equilibrium under the different conditions of finanical market.

The real interest sensitivity of aggregate demand in the IS curve can be positive under the financial market imperfection, because agents' intertemporal substituion is likely to be disturbed by the imperfection. If so, then the Taylor principle can be unessential for determinacy. First, the Taylor principle is sufficient but not necessary for determinacy if the central bank responds to current inflation; that is, the bank need not be so active as the Taylor principle. Second, the Taylor principle is neither necessary nor sufficient for determinacy if the central bank responds to expected inflation; the bank must not be so active as the Taylor principle. In addition, our calibration and estimation results suggest it dangerous that the central bank adheres solely to the Taylor principle when real financial markets are crucially immature or bankrupt such as the Japanese market during the 1990s.

\section{Appendix}

\section{A Derivation of Condition for Determinacy}

Our model can be reduced to a two variates dynamic stochastic system which includes two non-predetermined endogenous variables, by eliminating one variable from the model. For rational-expectations equilibrium to be determinate, the model must have exactly two eigenvalues outside the unit circle (Blanchard and Kahn[3]). This case of conditions are derived by Woodford[24, p.670], who shows that two eigenvalues $\delta_{1}, \delta_{2}$ are outside the unit circle if and only if either

$$
\left\{\begin{array}{l}
\delta_{1} \delta_{2}>1, \\
\left(\delta_{1}-1\right)\left(\delta_{2}-1\right)>0 \\
\left(\delta_{1}+1\right)\left(\delta_{2}+1\right)>0
\end{array}\right.
$$

or

$$
\left\{\begin{array}{l}
\left(\delta_{1}-1\right)\left(\delta_{2}-1\right)<0 \\
\left(\delta_{1}+1\right)\left(\delta_{2}+1\right)<0 .
\end{array}\right.
$$

Our determinacy conditions in Appendix B and $\mathrm{C}$ are calculated from the above inequalities. 


\section{B Determinacy Conditions of the Current-looking Rule}

Eliminating one endogenous variable from the model Eqs. (17), (20), (21), we obtain the following two eigenvalues of the model:

$$
\delta_{k}=\frac{1}{2 \sigma}\left(j_{1} \pm \sqrt{j_{2}}\right), \quad k=1,2
$$

where $j_{1}=1+\sigma+\lambda-\mu(1-\sigma)(1+\lambda(1-\sigma)), j_{2}=(1+\sigma+\lambda-\mu(1-\sigma)(1+\lambda(1-$ $\sigma)))^{2}-4 \sigma\left(1+\lambda \phi_{\pi}-\mu(1-\sigma)\left(1+\lambda \phi_{\pi}(1-\sigma)\right)\right)$.

Using Eqs. (25)-(26), we can derive the following necessary and sufficient conditions for determinate equilibrium:

$$
\left\{\begin{array}{l}
\lambda \phi_{\pi}\left(1-\mu(1-\sigma)^{2}\right)+(1-\sigma)(1-\mu)+\sigma(1-\beta)>0 \\
\lambda\left(\phi_{\pi}-1\right)\left(1-\mu(1-\sigma)^{2}\right)+(1-\beta)(1-\sigma)(1-\mu)>0 \\
\lambda\left(\phi_{\pi}+1\right)\left(1-\mu(1-\sigma)^{2}\right)+(1+\beta)(1+\sigma-\mu(1-\sigma))>0
\end{array}\right.
$$

or

$$
\left\{\begin{array}{l}
\lambda\left(\phi_{\pi}-1\right)\left(1-\mu(1-\sigma)^{2}\right)+(1-\beta)(1-\sigma)(1-\mu)<0, \\
\lambda\left(\phi_{\pi}+1\right)\left(1-\mu(1-\sigma)^{2}\right)+(1+\beta)(1+\sigma-\mu(1-\sigma))<0 .
\end{array}\right.
$$

With $z_{0} \equiv 1-\frac{(1-\beta)(1-\sigma)(1-\mu)}{\lambda\left(1-\mu(1-\sigma)^{2}\right)}, z_{1} \equiv-\frac{(1-\sigma)(1-\mu)+\sigma(1-\beta)}{\lambda\left(1-\mu(1-\sigma)^{2}\right)}$, and $z_{2} \equiv-1-$ $\frac{(1+\beta)(1+\sigma-\mu(1-\sigma))}{\lambda\left(1-\mu(1-\sigma)^{2}\right)}$, we can derive the determinacy conditions of the response coefficient $\phi_{\pi}$ under the different conditions of financial market in the next three subsections.

\section{B.1 Conditions in the Perfect Market $(\mu=1)$}

Eqs. (27) are all satisfied if and only if $\phi_{\pi}>\max \left\{0, z_{0}, z_{1}, z_{2}\right\}$, and Eqs. (28) satisfied if and only if $0<\phi_{\pi}<\min \left\{z_{0}, z_{2}\right\}$. If $0<\sigma<2$ and $\mu=1$, then $z_{1}<0, z_{0}=1$, and $z_{2}<0$. Then, $\max \left\{0, z_{0}, z_{1}, z_{2}\right\}$ is reduced to 1 , and $0<\phi_{\pi}<$ $\min \left\{z_{0}, z_{2}\right\}$ is not satisfied with any $\phi_{\pi}$. As a result, the determinacy condition in the perfect market is reduced to Eq. (23).

\section{B.2 Conditions in the Concave Market $(0<\mu<1)$}

Eqs. (27) are all satisfied if and only if $\phi_{\pi}>\max \left\{0, z_{0}, z_{1}, z_{2}\right\}$, and Eqs. (28) satisfied if and only if $0<\phi_{\pi}<\min \left\{z_{0}, z_{2}\right\}$. If $\beta \approx 1,0<\sigma<2$, and $0<\mu<1$, then $z_{0} \approx 1$ and $z_{2}<0$. Then, $\max \left\{0, z_{0}, z_{1}, z_{2}\right\}=\max \left\{1, z_{1}, z_{2}\right\}$, and $0<\phi_{\pi}<$ $\min \left\{z_{0}, z_{2}\right\}$ is not satisfied with any $\phi_{\pi}$. As a result, the determinacy condition in the concave market is reduced to Lemma 2 .

\section{B.3 Conditions in the Convex Market $(\mu>1)$}

Conditions satisfying Eqs. (27)-(28) depend upon the values of $\sigma$ and $\mu$ as follows: 
1. For $0<\sigma \leqq 1-\frac{1}{\sqrt{\mu}}$ :

Eqs. (27) are all satisfied if and only if $0<\phi_{\pi}<\min \left\{z_{0}, z_{1}, z_{2}\right\}$, and Eqs. (28) satisfied if and only if $\phi_{\pi}>\max \left\{0, z_{0}, z_{2}\right\}$. If $\beta \approx 1$ and $\mu>1$, then $z_{0} \approx 1$, $z_{1}<0$, and $z_{2}<0$. Then, $0<\phi_{\pi}<\min \left\{z_{0}, z_{1}, z_{2}\right\}$ is not satisfied with any $\phi_{\pi}$, and $\max \left\{0, z_{0}, z_{2}\right\}=\max \left\{1, z_{1}, z_{2}\right\}$. As a result, the determinacy condition is summarized as $\phi_{\pi}>\max \left\{1, z_{1}, z_{2}\right\}$.

2. For $1-\frac{1}{\sqrt{\mu}}<\sigma<\frac{\mu-1}{\mu+1}$ :

Eqs. (27) are all satisfied if and only if $\phi_{\pi}>\max \left\{0, z_{0}, z_{1}, z_{2}\right\}$, and Eqs. (28) all satisfied if and only if $0<\phi_{\pi}<\min \left\{z_{0}, z_{2}\right\}$. If $\beta \approx 1$ and $\mu>1$, then $z_{0} \approx 1$ and $z_{1}>z_{2}$. Then, $\min \left\{z_{0}, z_{2}\right\}=\min \left\{1, z_{1}, z_{2}\right\}$. As a result, the determinacy conditions are summarized as $\phi_{\pi}>\max \left\{1, z_{1}, z_{2}\right\}$ or $0<\phi_{\pi}<$ $\min \left\{1, z_{1}, z_{2}\right\}$.

3. For $\frac{\mu-1}{\mu+1} \leqq \sigma \leqq 1+\frac{1}{\sqrt{\mu}}$ :

Eqs. (27) are all satisfied if and only if $\phi_{\pi}>\max \left\{0, z_{0}, z_{1}, z_{2}\right\}$, and Eqs. (28) all satisfied if and only if $0<\phi_{\pi}<\min \left\{z_{0}, z_{2}\right\}$. If $\beta \approx 1$ and $\mu>1$, then $z_{0} \approx 1$ and $z_{2}<0$. Then, $0<\phi_{\pi}<\min \left\{z_{0}, z_{2}\right\}$ is not satisfied with any $\phi_{\pi}$. As a result, the determinacy condition is summarized as $\phi_{\pi}>\max \left\{1, z_{1}, z_{2}\right\}$.

4. For $1+\frac{1}{\sqrt{\mu}}<\sigma<2$ :

Eqs. (27) are all satisfied if and only if $0<\phi_{\pi}<\min \left\{z_{0}, z_{1}, z_{2}\right\}$, and Eqs. (28) all satisfied if and only if $\phi_{\pi}>\max \left\{0, z_{0}, z_{2}\right\}$. If $\beta \approx 1$ and $\mu>1$, then $z_{0} \approx 1$ and $z_{1}<z_{2}$. Then, $\max \left\{0, z_{0}, z_{2}\right\}=\max \left\{1, z_{1}, z_{2}\right\}$. As a result, the determinacy conditions are summarized as $0<\phi_{\pi}<\min \left\{1, z_{1}, z_{2}\right\}$ or $\phi_{\pi}>\max \left\{1, z_{1}, z_{2}\right\}$.

In summary, the determinacy conditions in the convex market are summarized as Lemma 3.

\section{Determinacy Conditions of the Forward-looking Rule}

Eliminating one endogenous variable from the model Eq. (17), (20), (22), we obtain the following two eigenvalues of the model:

$$
\delta_{k}=\frac{1}{2 \sigma}\left(j_{3} \pm \sqrt{j_{4}}\right), \quad k=1,2,
$$

where $j_{3} \equiv 1+\sigma-\lambda\left(\phi_{\pi}-1\right)-\mu(1-\sigma)\left(1-\lambda(1-\sigma)\left(\phi_{\pi}-1\right)\right), j_{4} \equiv\left(1+\sigma-\lambda\left(\phi_{\pi}-\right.\right.$ 1) $\left.-\mu(1-\sigma)\left(1-\lambda(1-\sigma)\left(\phi_{\pi}-1\right)\right)\right)^{2}-4 \sigma(1-\mu(1-\sigma))$.

Using Eq. (25)-(26), we can derive the following necessary and sufficient conditions for determinate equilibrium:

$$
\left\{\begin{array}{l}
(1-\sigma)(1-\mu)+\sigma(1-\beta)>0, \\
\lambda\left(\phi_{\pi}-1\right)\left(1-\mu(1-\sigma)^{2}\right)+(1-\beta)(1-\sigma)(1-\mu)>0, \\
-\lambda\left(\phi_{\pi}-1\right)\left(1-\mu(1-\sigma)^{2}\right)+(1+\beta)(1+\sigma-\mu(1-\sigma))>0
\end{array}\right.
$$


or

$$
\left\{\begin{array}{l}
\lambda\left(\phi_{\pi}-1\right)\left(1-\mu(1-\sigma)^{2}\right)+(1-\beta)(1-\sigma)(1-\mu)<0, \\
-\lambda\left(\phi_{\pi}-1\right)\left(1-\mu(1-\sigma)^{2}\right)+(1+\beta)(1+\sigma-\mu(1-\sigma))<0 .
\end{array}\right.
$$

With $z_{0} \equiv 1-\frac{(1-\beta)(1-\sigma)(1-\mu)}{\lambda\left(1-\mu(1-\sigma)^{2}\right)}$ and $z_{3} \equiv 1+\frac{(1+\beta)(1+\sigma-\mu(1-\sigma))}{\lambda\left(1-\mu(1-\sigma)^{2}\right)}$, we can derive the determinacy conditions of the response coefficient $\phi_{\pi}$ under the different conditions of financial market in the next three subsections.

\section{C.1 Conditions in the Perfect Market $(\mu=1)$}

Eqs. (29) are all satisfied if and only if $\max \left\{0, z_{0}\right\}<\phi_{\pi}<z_{3}$, and Eqs. (30) all satisfied if and only if $\max \left\{0, z_{3}\right\}<\phi_{\pi}<z_{0}$. If $0<\sigma<2$ and $\mu=1$, then $z_{3}>1$ and $z_{0}=1$. Then, $\max \left\{0, z_{0}\right\}<\phi_{\pi}<z_{3}$ is reduced to $1<\phi_{\pi}<z_{3}$, while $\max \left\{0, z_{3}\right\}<\phi_{\pi}<z_{0}$ is not satisfied with any $\phi_{\pi}$. As a result, the determinacy condition in the perfect market is reduce to Eq. (24).

\section{C.2 Conditions in the Concave Market $(0<\mu<1)$}

Conditions satisfying Eqs. (29)-(30) depend upon the values of $\sigma$ and $\mu$ as follows:

1. For $0<\sigma \leqq 1$ :

Eqs. (29) are all satisfied if and only if $\max \left\{0, z_{0}\right\}<\phi_{\pi}<z_{3}$, and Eqs. (30) all satisfied if and only if $\max \left\{0, z_{3}\right\}<\phi_{\pi}<z_{0}$. If $\beta \approx 1$ and $0<\mu<1$, then $z_{3}>1$ and $z_{0} \approx 1$. Then, $\max \left\{0, z_{0}\right\}<\phi_{\pi}<z_{3}$ is reduced to $1<\phi_{\pi}<z_{3}$, while $\max \left\{0, z_{3}\right\}<\phi_{\pi}<z_{0}$ is not satisfied with any $\phi_{\pi}$. As a result, the determinacy condition is summarized as $1<\phi_{\pi}<z_{3}$.

2. For $1<\sigma<2$ :

Eqs. $(29)$ are not satisfied with any $\phi_{\pi}$ because $(1-\sigma)(1-\mu)+\sigma(1-\beta)<0$ under $\beta \approx 1$, and Eqs. (30) all satisfied if and only if $\max \left\{0, z_{3}\right\}<\phi_{\pi}<z_{0}$. If $\beta \approx 1$ and $0<\mu<1$, then $z_{3}>z_{0}$. Then, $\max \left\{0, z_{3}\right\}<\phi_{\pi}<z_{0}$ is not satisfied with any $\phi_{\pi}$. As a result, the determinacy condition does not exist under $1<\sigma<2$.

In summary, the determinacy conditions in the concave market are summarized as Lemma 5.

\section{C.3 Conditions in the Convex Market $(\mu>1)$}

Conditions satisfying Eqs. (29)-(30) depend upon the values of $\sigma$ and $\mu$ as follows:

1. For $0<\sigma \leqq 1-\frac{1}{\sqrt{\mu}}$ :

Eqs. (29) are all satisfied if and only if $\max \left\{0, z_{3}\right\}<\phi_{\pi}<z_{0}$, and Eqs. (30) all satisfied if and only if $\max \left\{0, z_{0}\right\}<\phi_{\pi}<z_{3}$. If $\beta \approx 1$ and $\mu>1$, then $z_{3}>z_{0}$ and $z_{0} \approx 1$. Then, $\max \left\{0, z_{3}\right\}<\phi_{\pi}<z_{0}$ is not satisfied with any $\phi_{\pi}$. As a result, the determinacy condition is reduced to $1<\phi_{\pi}<z_{3}$. 
2. For $1-\frac{1}{\sqrt{\mu}}<\sigma \leqq \frac{\mu-1}{\mu+1}$ :

Eqs. (29) are all satisfied if and only if $\max \left\{0, z_{0}\right\}<\phi_{\pi}<z_{3}$, and Eqs. (30) all satisfied if and only if $\max \left\{0, z_{3}\right\}<\phi_{\pi}<z_{0}$. If $\beta \approx 1$ and $\mu>1$, then $z_{3}<z_{0}$ and $z_{0} \approx 1$. Then, $\max \left\{0, z_{0}\right\}<\phi_{\pi}<z_{3}$ is not satisfied with any $\phi_{\pi}$. As a result, the determinacy condition is reduced to $\max \left\{0, z_{3}\right\}<\phi_{\pi}<1$.

3. For $\frac{\mu-1}{\mu+1}<\sigma<1$ :

Eqs. (29) are not satisfied with any $\phi_{\pi}$ because $(1-\sigma)(1-\mu)+\sigma(1-\beta)<0$ under $\beta \approx 1$, and Eqs. (30) all satisfied if and only if $\max \left\{0, z_{3}\right\}<\phi_{\pi}<z_{0}$. If $\beta \approx 1$ and $\mu>1$, then $z_{3}>z_{0}$. Then, $\max \left\{0, z_{3}\right\}<\phi_{\pi}<z_{0}$ is not satisfied with any $\phi_{\pi}$. As a result, the determinacy condition does not exist under $\frac{\mu-1}{\mu+1}<\sigma<1$.

4. For $1 \leqq \sigma \leqq 1+\frac{1}{\sqrt{\mu}}$ :

Eqs. (29) are all satisfied if and only if $\max \left\{0, z_{0}\right\}<\phi_{\pi}<z_{3}$, and Eqs. (30) all satisfied if and only if $\max \left\{0, z_{3}\right\}<\phi_{\pi}<z_{0}$. If $\beta \approx 1$ and $\mu>1$, then $z_{0}<z_{3}$ and $z_{0} \approx 1$. Then, $\max \left\{0, z_{3}\right\}<\phi_{\pi}<z_{0}$ is not satisfied with any $\phi_{\pi}$. As a result, the determinacy condition is reduced to $1<\phi_{\pi}<z_{3}$.

5. For $1+\frac{1}{\sqrt{\mu}}<\sigma<2$ :

Eqs. (29) are all satisfied if and only if $\max \left\{0, z_{3}\right\}<\phi_{\pi}<z_{0}$, and Eqs. (30) all satisfied if and only if $\max \left\{0, z_{0}\right\}<\phi_{\pi}<z_{3}$. If $\beta \approx 1$ and $\mu>1$, then $z_{3}<z_{0}$ and $z_{0} \approx 1$. Then, $\max \left\{0, z_{0}\right\}<\phi_{\pi}<z_{3}$ is not satisfied with any $\phi_{\pi}$. As a result, the determinacy condition is reduced to $\max \left\{0, z_{3}\right\}<\phi_{\pi}<1$.

In summary, the determinacy conditions in the convex market are summarized as Lemma 6.

\section{Estimation of the Paramter $\mu$}

Using Eq. (4), (9), $R_{1, t}=R_{t} \Omega\left(\frac{-B_{1, t}}{P_{t}}\right)$. It is log-linearized to

$$
r_{1, t}-r_{t}=\frac{1-\mu}{\mu}\left(\log \left(\frac{-B_{1, t}}{P_{t}}\right)-\log \left(\frac{-B_{1}}{P}\right)\right) .
$$

Then we estimate the paramter $\mu$ using the following Japanese financial data, which is taken from the Nikkei NEEDS Macroeconomic Data File. First, the interest rate spread $r_{1, t}-r_{t}$ is calculated with average contracted interest rates on new loan by domestic banks and uncollaterized overnight call rate. The real borrowing $-B_{1, t} / P_{t}$ is taken from the first difference of loans outstanding by domestic banks denominated with CPI. The method of estimation is the generalized method of moments. Table 1 shows our results. 


\section{References}

[1] Bernanke,B. and A.Blinder, "Credit, Money, and Aggregate Demand," American Economic Review, Vol.78, No.2, 1988, pp.435-439.

[2] Bernanke,B.S. and M.Woodford, "Inflation Forecasts and Monetary Policy," Journal of Money, Credit, and Banking, Vol.29, No.4, 1997, pp.653-685.

[3] Blanchard,O.J. and C.M.Kahn, "The Solution of Linear Difference Models under Rational Expectations," Econometrica, Vol.48, No.5, 1980, pp.1305-1311.

[4] Calvo,G.A., "Staggered Prices in a Utility-Maximizing Framework," Journal of Monetary Economics, Vol.12, 1983, pp.383-398.

[5] Carlstrom,C.T. and T.S.Fuerst, "Investment and Interest Rate Policy: A Discrete Time Analysis," Journal of Economic Theory, Vol.123, No.1, 2005, pp.4-20.

[6] Clarida,R., J.Gali, and M.Gertler, "The Science of Monetary Policy: A New Keynesian Perspective," Journal of Economic Literature, Vol.37, 1999, pp.1661-1707.

[7] Clarida,R., J.Gali, and M.Gertler, "Monetary Policy Rules and Macroeconomic Stability: Evidence and Some Theory," Quarterly Journal of Economics, Vol.115,Iss.1, 2000, pp.147-180.

[8] Dupor,B., "Investment and Interest Rate Policy," Journal of Economic Theory, Vol.98, No.1, 2001, pp.85-113.

[9] Gali,J. and M.Gertler, "Inflation Dynamics: A Structural Econometric Analysis," Journal of Monetary Economics, Vol.44, Iss.2 1999, pp.195-222.

[10] Kiley, M.T., "Is Moderate-to-High Inflation Inherently Unstable?" Finance and Economics Discussion Series, No.2004-43, The Federal Reserve Board, 2004.

[11] Kitamura,Y., and Fujiki,H., "Sapurai-saido jyouhou wo riyoushita Shouhi ni motoduku Shihon-shisan-kakaku-kettei Moderu no Suikei," [Estimation of the CCAPM Using Information on the Supply Side], Kinyu Kenkyu No.16, Bank of Japan, 1997, pp.29-42.

[12] Kozuka,M., "Consumer Behavior in Japan and its Structural Change: Reexamination by Sup-predictive Test," RIEB Discussion Paper Series, No.183, Kobe University, 2006.

[13] Ogaki,M., and Reinhart,C.M., "Measuring Intertemporal Substitution: The Role of Durable Goods," Journal of Political Economy, Vol.106,No.5, 1998, pp.1078-1098.

[14] Ogawa,K. and S.Kitasaka, "Bank Lending in Japan: Its Determinants and Macroeconomic Implications," in Hoshi,T. and H. Patrick eds., Crisis and Change in the Japanese Financial System, Kruwer Academic Publishers, 2000.

[15] Okubo,M., "Intertemporal Substitution and Consumer Durables: An Analysis Based on Japanese Data," Institute of Policy and Planned Sciences Working Paper, No.1016, Tsukuba University, 2002. 
[16] Samuelson,P.A., "An Exact Consumption-Loan Model of Interest with or without the Social Contrivance of Money," Journal of Political Economy, Vol.66, No.6, 1958, pp.467-482.

[17] Sargent,T.J. and N.Wallace, "'Rational" Expectations, the Optimal Monetary Instrument, and the Optimal Money Supply Rule," Journal of Political Economy, Vol.83, No.2, 1975, pp.241-254.

[18] Sveen,T. and L.Weinke, "New Perspectives on Capital, Sticky Prices, and the Taylor Principle," Journal of Economic Theory, Vol.123, No.1, 2005, pp.21-39.

[19] Taylor,J.B., "Discretion versus Policy Rules in Practice," Carnegie-Rochester Conference Series on Public Policy, Vol.39, 1993, pp.195-214.

[20] Taylor,J.B., "The Inflation/Output Variability Trade-off Revisited," in Fuhrer,J.C., ed., Goal, Guidelines, and Constraints Facing Monetary Policymakers, Federal Reserve Bank of Boston, 1995.

[21] Taylor,J.B., "A Historical Analysis of Monetary Policy Rules," in Taylor,J.B. ed., Monetary Policy Rules, University of Chicago Press, 1999,pp.319-341.

[22] Tuladhar,A., "Monetary Policy Under Imperfect Capital Markets in a Small Open Economy," American Economic Review, Vol.93, No.2, 2003, pp.266-270.

[23] Vissing-Jorgensen,A. "Limited Asset Market Participation and the Elasticity of Intertemporal Substitution," Journal of Political Economy, Vol.110,No.4, 2002.

[24] Woodford,M., Interest and Prices: Foundations of a Theory of Monetary Policy, Princeton University Press, 2003. 
Table 1 Estimates of the Parameter $\mu$

\begin{tabular}{c|ccccc}
\hline Type of borrowers & All industries & Manufacturing & $\begin{array}{c}\text { Wholesale \& } \\
\text { Retail Trade }\end{array}$ & Construction & Real estate \\
\hline$\mu$ & $\begin{array}{c}1.607^{* *} \\
(.320)\end{array}$ & $\begin{array}{c}1.099^{*} \\
(.056)\end{array}$ & $\begin{array}{c}1.034 \\
(.030)\end{array}$ & $\begin{array}{c}1.382^{* * *} \\
(.099)\end{array}$ & $\begin{array}{c}1.336^{* *} \\
(.155)\end{array}$ \\
\hline
\end{tabular}

Note: This table reports GMM estimates of the parameter $\mu$. Estimates are based on quarterly data and cover the sample period 1990:1-1999:4. The data is available in the Nikkei NEEDS Macroeconomic Data File. Deterministic variables are a constant term and seasonal dummies. Instruments used in the estimations include four lags of endogenous variables. Conditional heteroskedasticity and fourth-order autocorrelation in standard errors are permitted in the estimations. The tests of overidentifying

restrictions are not rejected. The signs $* * *, * *$, and * represent significantly different from one at $1 \%$, $5 \%, 10 \%$ level, respectively. The values in parentheses are standard errors. 
Figure 1 Financial Market Imperfection

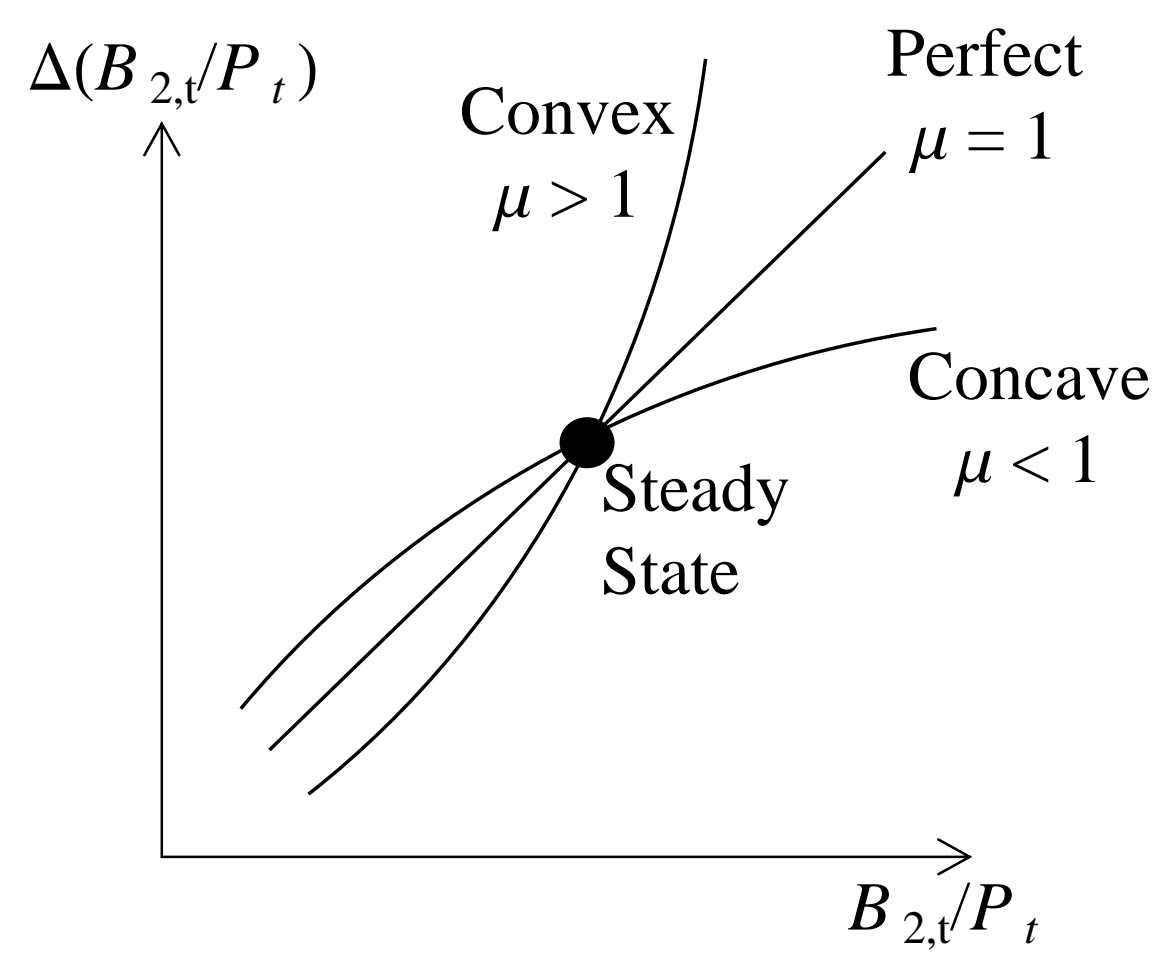


Figure 2 Determinacy Conditions of the Current-looking Rule

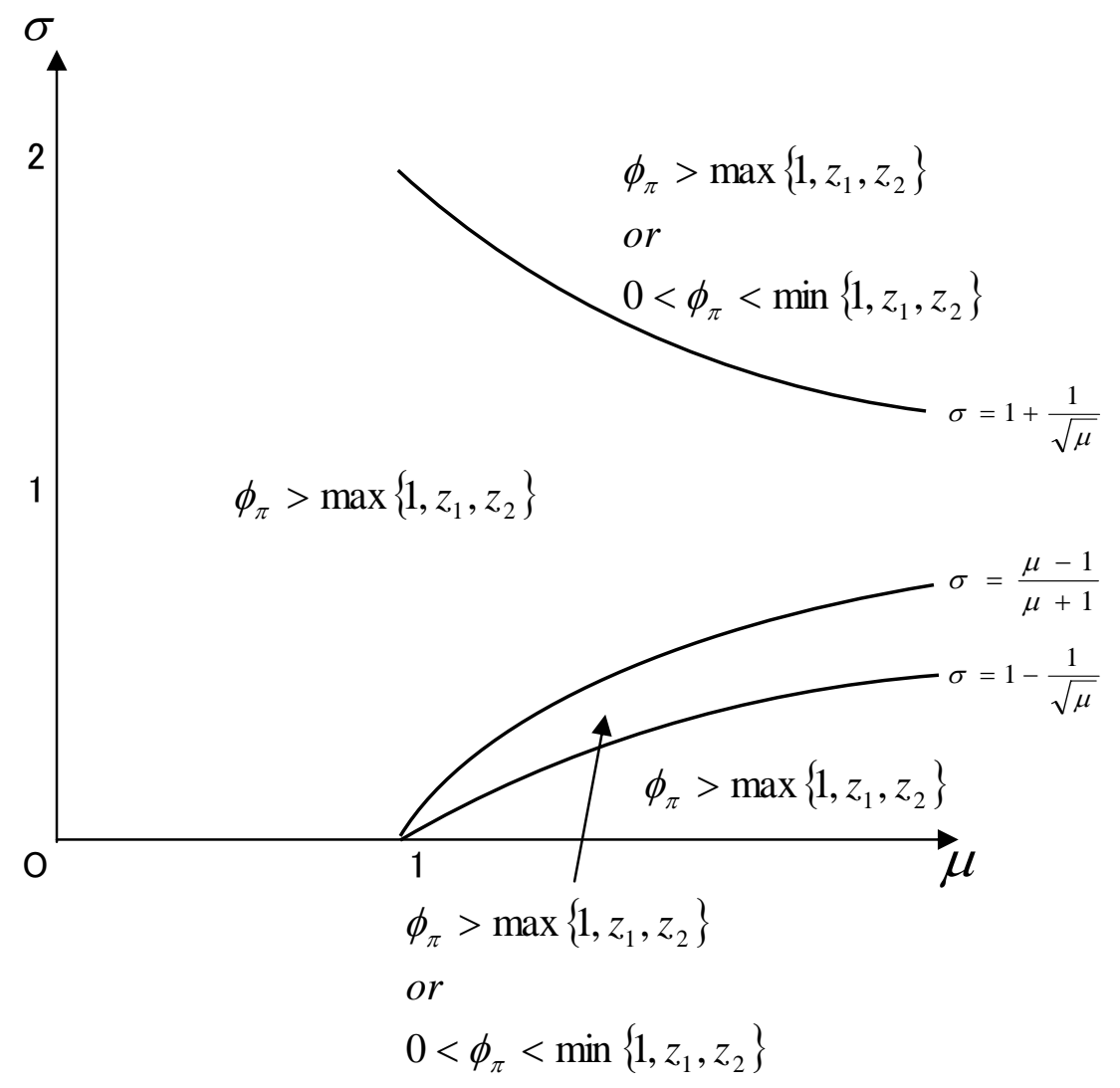


Figure 3 Determinacy Conditions of the Forward-looking Rule

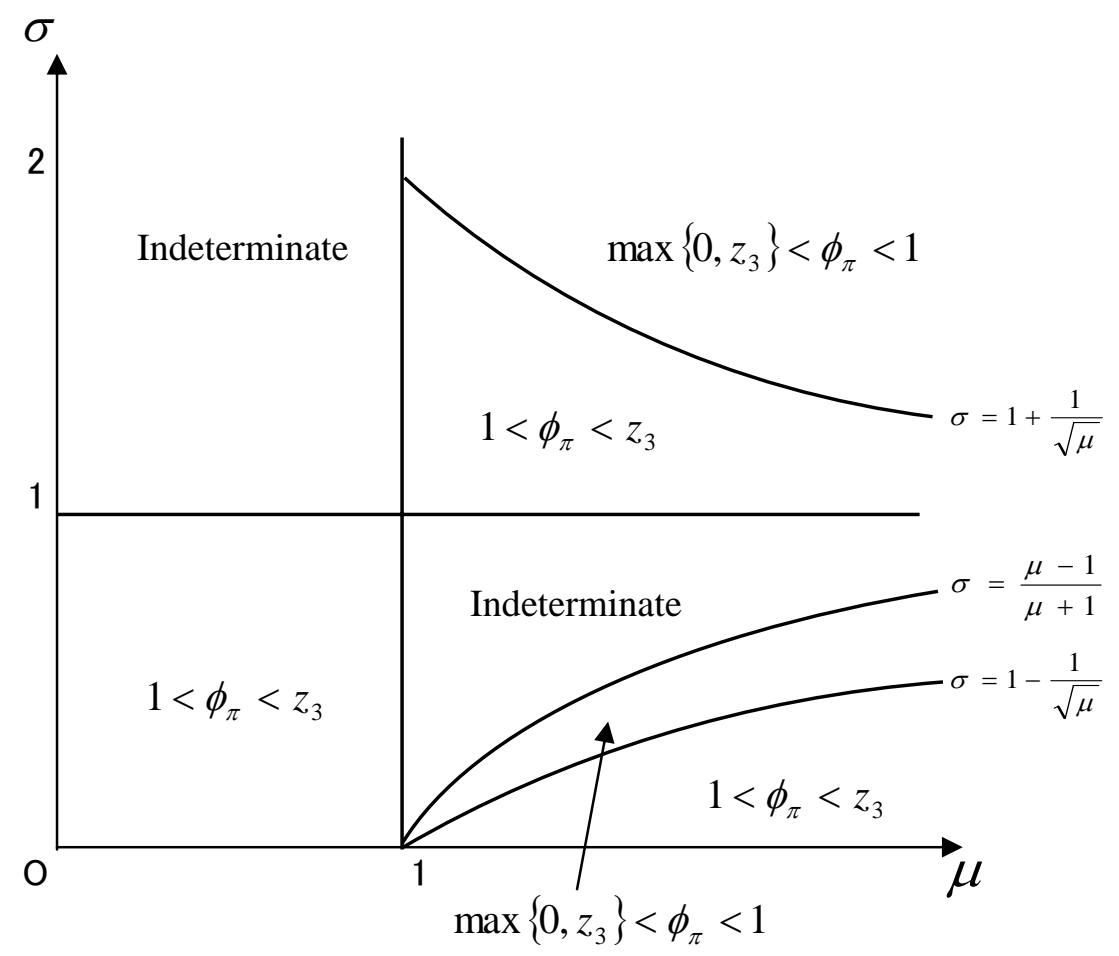


Figure 4 Calibration of the Response Coefficient $\phi_{\pi}$ Ensuring Determinacy

(a) Current-looking Rule

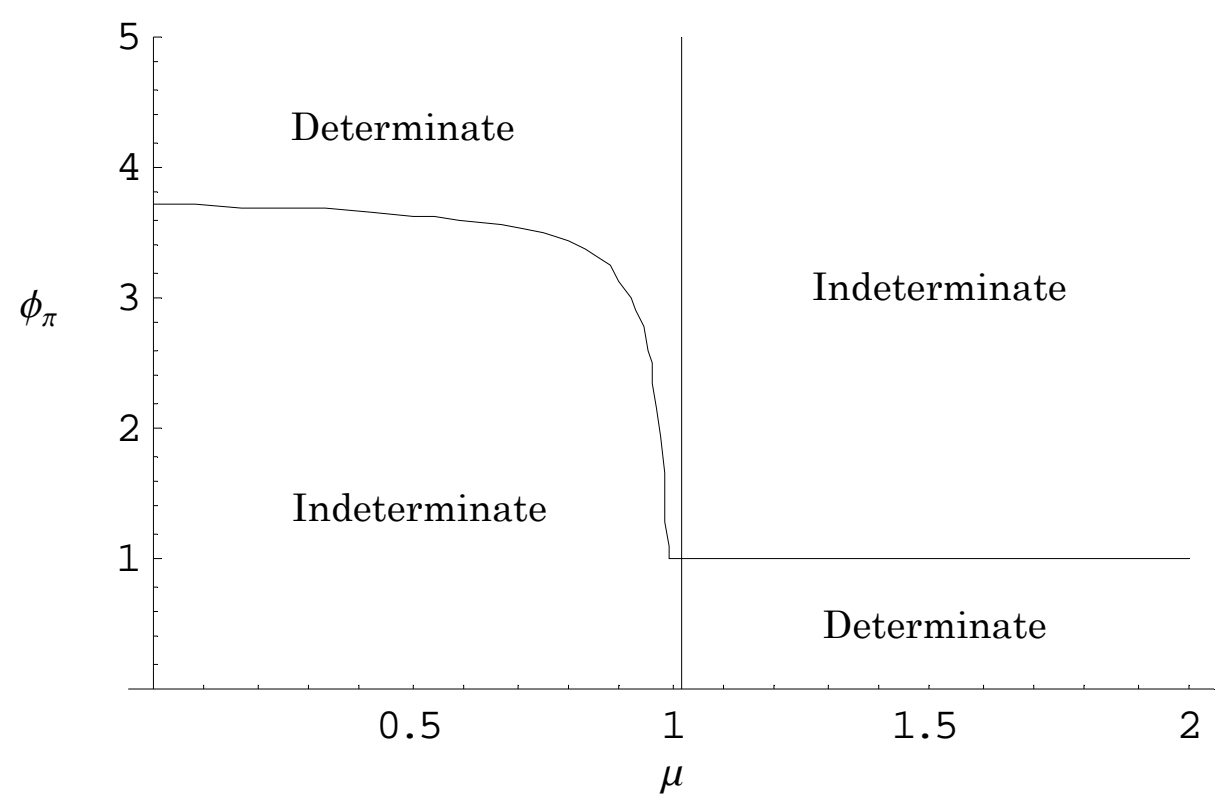

(b) Forward-looking Rule

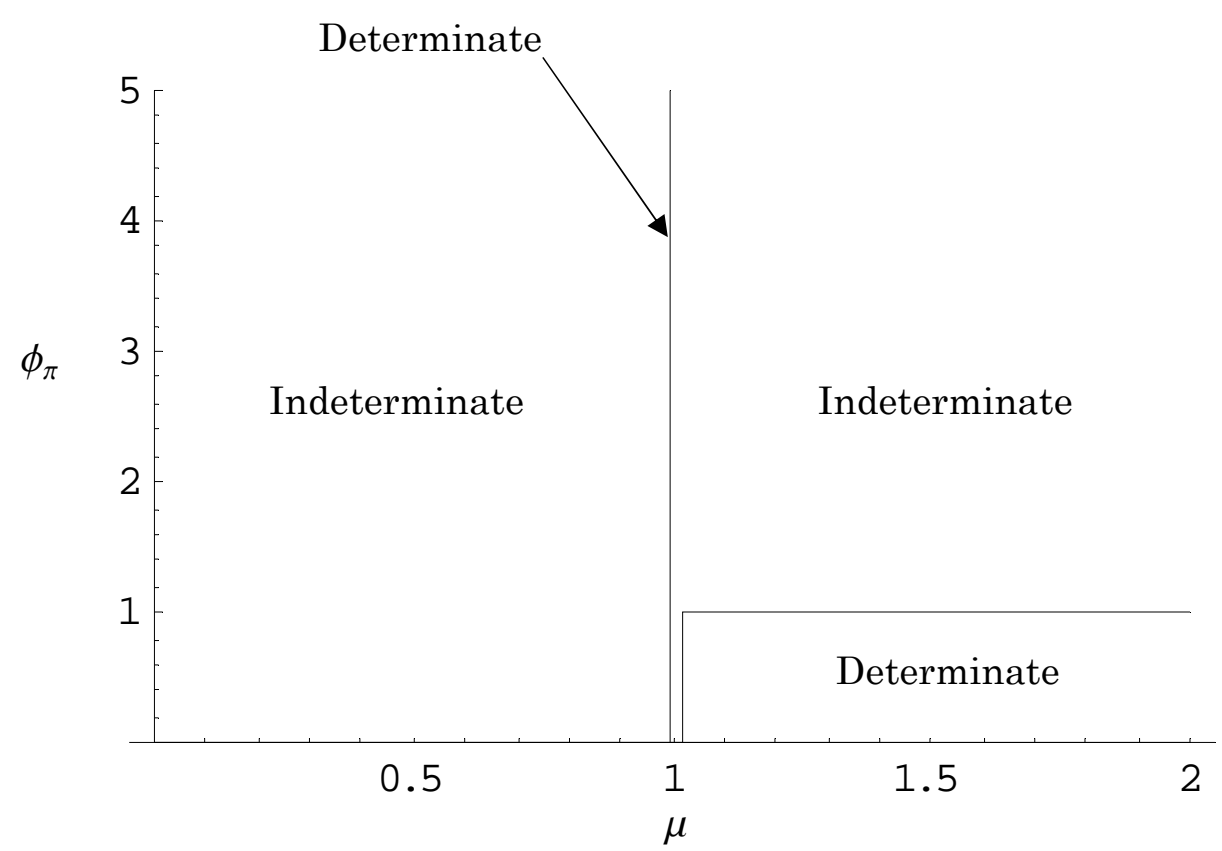

